\title{
Anthropogenic impacts to critical zone processes in urban watersheds
}

\author{
SARA PHELPS $^{1 *}$, TODD OSBORNE ${ }^{1}$ \\ ${ }^{1}$ Soil and Water Sciences Dept., University of Florida, \\ Gainesville, FL (*correspondence: saraphelps@ufl.edu) \\ While hydrology is a science rooted in critical zone \\ concepts, hydrochemical and ecohydrology \\ observations highlight the need to integrate geological, \\ geomorphological, and pedological understanding into \\ hydrological partitioning. In urban watersheds, \\ stormwater management has resulted in increased flows \\ and altered subsidies and fluxes with extensive \\ headwater alteration and increased hydrologic \\ connectivity between headwaters and streams. We \\ explore a catchment nutrient budget approach rooted in \\ synthesis science that moves beyond an assessment of \\ landscape-based nutrient sources and incorporates \\ integrated hydrologic processes to improve the ability \\ to adapt management to external forces. This \\ framework captures critical zone processes as \\ processors and drivers of water quality in watersheds \\ and to serve as a tool to guide watershed studies. \\ Using a case study in a southeastern US watershed, \\ we apply this framework to explore previously \\ unaddressed nonpoint source pollution in the form of \\ sediment erosion and transport. Based on an initial \\ hydrologic synthesis of the watershed, a sediment \\ fingerprinting study was developed to partition \\ sediments from the surface (landscape-derived) and \\ those derived from the sub-surface as phosphate \\ minerals transported by stream bank erosion processes. \\ Findings suggest that increased channel velocities, \\ resulting from land use change and increased \\ populations, have increased within-channel erosion \\ resulting in the exposure and transport of geologic \\ phosphate minerals. We discuss the implications of \\ land use change and erosion processes on critical zone \\ processes in urban watersheds and potential \\ consequences to surface waters in similar settings.
}

